\title{
Female students' drinking seen through collages and diaries
}

\section{Introduction}

Heavy alcohol consumption among young people remains one of the most important social problems in most developed countries (Szmigin et al., 2008). Social marketing research in this area is largely concerned with the most urgent social needs, such us: public health (Wechsler and Nelson, 2008; Cismaru et al., 2008), injuries including car accidents (Park, 2004; Wechsler and Nelson, 2008), drink-driving (Park, 2004), sexual assaults (Hill et al., 2005) and family and other social problems (Cismaru et al., 2008; Hill et al., 2005). Although young people's drinking has been looked at from a variety of angles and theoretical perspectives over the last 20 years (Wechsler and Nelson, 2008), the problem still remains unresolved. In Poland, where the research reported in this paper was carried out, binge drinking among university students is on the rise (Makara-Studzinska and Urbańska, 2007). Further, female students have been identified as a much higher-risk group when it comes to alcohol use, compared to non-students in the same age group (Kypri et al., 2005). Therefore, utilising visual and ethnographic methodologies, this paper investigates young female consumers' motivations and perceptions of their alcohol consumption in the context of the changing drinking culture among women.

\section{Literature review}

Gender remains one of the most important aspects of consumer behaviour (Fischer, 2002), and has received significant attention from researchers in the consumer culture area (Otnes and McGrath, 2001; Woodruffe-Burton et al., 2002). However, in the last two decades, a convergence between male and female consumption behaviours has been observed, in particular among young adults who are becoming increasingly similar, with gendered consumption boundaries disappearing in many consumption contexts. For example, Cuneo (1997) identified growing interests in women among advertisers following a sharp increase in women's consumption of traditionally male-dominated sport services and products, and O'Donnell et al. (1998) observed similar patterns in the consumption of entertainment and leisure activities.

Heavy alcohol consumption among young people has been widely studied in the last decade, and similar converging changes have been observed in this area. While there is a considerable body of knowledge relating to drinking motives and the negative consequences of binge drinking, much less attention has been directed towards the changes in drinking culture among young women (Wechsler et al., 2002). Alcohol also used to be considered a gendered product (Iyer and Debevec, 1986; Rolfe et al., 2009), and although gender differences in drinking styles and the amount of alcohol consumed are still visible in many countries (Dantzer et al., 2006), the changing drinking culture and the convergence of male and female alcohol consumption have been identified by some as increasingly important and relevant with respect to understanding young people's drinking (Carpenter et al., 2007). For example, regular surveys in Ireland show that differences in the proportions of female and male drinkers have been disappearing since the 1970s, and no differences were observed in the latest survey, conducted in 2002 (Boland et al., 2006). Crucially, a significant increase of problems associated with alcohol consumption among females was noted in the decade before the study took place (ibid.). Similar issues have been also observed in Britain (Rickards et al., 2004), where heavy alcohol consumption was reported among increasing numbers of women (Alcohol Concern, 2003) 
Young et al. (2005) conducted a comprehensive literature review on gender differences with regards to the reasons for drinking reported by college students. Although earlier studies indicate that male students were more likely to engage in binge drinking than their female peers (O'Malley and Johnston, 2002), Young et al.'s (2005) review suggests that the gap is diminishing. The 'European School Survey Project on Alcohol and Other Drugs' (ESPAD) even indicates that excessive alcohol consumption has become more common among girls than boys (2007). This convergence of male and female alcohol consumption has been linked by some to women's growing independence (Measham and Ostergaard, 2009). Women's lives, the argument runs, are becoming increasingly similar to men's in terms of their work and leisure patterns, leading to male students' alcohol consumption patterns being mirrored by their female counterparts (Bloomfield et al., 2001; Roche and Deehan, 2002). Further, Young et al. (2005) extended the argument by claiming that female students' drinking is not simply about gender equality, but above all emphasises their (hetero)sexuality, attracting positive attention from their male peers, and raising their social position among male drinking groups. Therefore, as mixed-gender friendships have become more common, women's primary motivation to drink is not to be like men, but to be liked by men. Their motivation has been attributed to the belief that their male friends want women to binge drink and find heavy drinking attractive. That belief, however, is inconsistent with men's perception of women who get drunk, as reported by Parks and Scheidt (2000). Berkowitz and Perkins (1987) also argue that women are more likely than men to overestimate other students' acceptance of heavy alcohol consumption.

Part of the growing problem with increasing alcohol consumption among women might be attributed to the fact that it used to be perceived as a 'taboo subject', which was associated with unfeminine and immoral behaviours (Plant, 1997; Rolfe et al., 2009), and was therefore rarely openly identified as a problem. Although recent research into female drinking attempts to uncover its causes, it shows that when contrasting female drinking to that of their male friends, women are often able to appropriate male drinking behaviours in a feminised way, i.e. assimilating heavy drinking into their female identities (Lyons et al., 2006; Lyons and Willott, 2008; Rolfe et al., 2009). However, despite growing evidence of the convergence between male and female alcohol consumption, female students in Rúdólfsdóttir and Morgan's (2009) research still associated problem drinking with men, so called 'chavvies', and disreputable women. Although the word 'chav' has a culturally-specific meaning in Britain, and per se would not be directly applicable to the cultural context of drinking in Poland, as a labeling statement it represents a term of abuse (Tyler, 2008), discursively creating an underclass characterised by social marginality and pathological consumption practices (Hayward and Yar, 2006). The use of this category by Rúdólfsdóttir and Morgan's (2009) female respondents indicates that young female students associate heavy alcohol consumption among women with social marginality, rather than their own consumption practices.

Young female drinkers claim to consume alcohol for its drug effects as well as to facilitate social interactions (McNeela and Bredin, 2010; Piacentini and Banister, 2006). In their review of drinking motives, Kuntsche et al. (2005) argue that young people drink to enhance their positive mood or well-being, obtain social rewards, attenuate negative emotions, and avoid social rejection. A similar list of drinking motives among college students was also identified by Read et al. (2003). Drinking to cope and reduce negative emotions has been identified as one of the key motives for drinking, and a strong predictor of alcohol use among female students (Kelly-Weeder, 2008), who use alcohol to reduce their anxiety and depression (Stewart et al., 2001). Park and Leveson's (2002) research in the US showed that drinking to cope is also related to high levels of alcohol consumption and episodes of heavy drinking. 
Although Tyssen et al. (1998) did not report any significant gender differences, their research also pointed towards the association between drinking to cope and hazardous drinking, emphasising drinking to cope as an important high-risk factor. Further, studies in Britain explore students' coping behaviours in alcohol-dominated situations (Piacentini and Banister, 2006; Piacentini and Banister, 2009). The Piacentini and Banister studies use Lazarus and Folkman's (1984) work on theories of appraisal and coping to understand the difference between three main coping strategies: problem-focused, emotion-focused, and social-supportfocused.

Kelly-Weeder and Edwards's (2011) research indicates that college-age women are more likely than men to experience negative consequences of heavy alcohol consumption; these consequences are personal in nature and largely related to problems with friends and dating partners. Similar conclusions can be found in Liu and Kaplan's (1996) research, which argues that women are more likely than men to drink at risky levels to ease their distress. In addition, Smith and Berger (2010) identify mood management as one of the main drinking motives among college women, while Pirkle and Richter's (2006) work indicates that teenage girls reporting depressive symptoms are more likely than less depressed girls to binge drink later. Finally, unhealthy dieting behaviours and self-perceptions of being overweight have been associated in earlier studies with increased alcohol consumption among women (Centre for Disease Control and Prevention, 1999). The last two decades have also witnessed some important research into the negative consequences of alcohol consumption. There is strong evidence that rates of alcohol-related problems among female students who engage in heavy alcohol consumption are very similar to those experienced by their male counterparts (Wechsler et al., 2000). For example, in their latest paper focused on students, Wechsler and Nelson (2008) propose four main categories of negative consequences: problems with academic performance, social relationships, risk-taking behaviours, and health. Smith and Berger (2010), in their study of female students, identify another important negative consequence associated with heavy alcohol consumption: 'getting emotional'. Finally, selfcontrol has been identified as a vital tool for reducing high-risk drinking and its negative consequences (Baumeister et al., 2007; Griffin et al., 2012; Posner and Rothbart, 2000).

\section{Research methods}

This article is based on a larger research project using qualitative research methods to investigate the role of alcohol consumption in students' lives. All participants were drawn from a pool of students studying at a university in the Polish city of Białystok. Only students who drink alcohol regularly were recruited to take part in the study. All data were collected in two phases: Phase 1 involved consumer diaries, and Phase 2 involved consumer collages. Although this research was exploratory in nature, the use of a mixed-method approach was intended to facilitate a more holistic view of the problem under investigation. A similar mixed-method qualitative research design was earlier employed by Piacentini and Banister (2006; 2009) in their research exploring students' coping strategies in alcohol-dominated situations, which used short essays followed by in-depth interviews. By employing a sequential design, which is dominant in multi-method marketing research (Harrison and Reilly, 2011), it was possible to treat Phase 1 as a preliminary stage that provided additional contextual information for the interpretation of data emerging from the collages in Phase 2. Further, the diary method made it possible to focus on individual alcohol consumption, while the collages explored the social side of the problem. The reality captured through this kind of mixed-method approach was 'socially constructed, multiple, holistic, [and] contextual' (Tadajewski, 2006, p. 438), and therefore provided an opportunity to explore informants' interactions with themselves, their families and other social groups, and their culture (Black, 
2006). Diaries, on the other hand, created the opportunity for informants to reflect on their everyday drinking behaviours and express opinions, feelings and emotions that, due to peer pressure, they may not have felt comfortable talking about among their friends when preparing and presenting their collages. Such peer pressure was deemed to play an important role in young people's consumption of alcohol.

In Phase 1, purposive sampling was used to establish a group of five female students, all aged 22 and regularly drinking alcohol, who grew up and lived in Białystok or the Podlasie region (north-east part of Poland). All participants were volunteers who were not rewarded for their participation in the research in any way, and their participation was not linked to any university assessment. The group was asked to keep individual written diaries. All of the participants are native Poles, so these diaries were kept in-country, in the Polish language. The task was relatively non-directive, with the aim of exploring what participants identified as being relevant to their alcohol consumption (Piacentini and Banister, 2006). The diaries were anonymous, and the respondents were only asked to write a short paragraph on the first page explaining their consumption patterns (e.g. how much they normally drink and how often), and then to always indicate the date and time of each entry; other than this instruction, the diarists were given no other template or format to follow. They were sensitized to the fact that they should behave as usual and change nothing in their everyday consumption habits. As the diaries were not designed to measure the participants' consumption levels, and in order to reduce the number of recorded observations to a manageable number, the diaries were limited to a two-week period. Furthermore, in order to avoid an over-prescriptive design, which was earlier described by Patterson (2005) as a 'straightjacket' which stifles informants' creativity and commitment to the research, our informants were merely instructed to keep a daily record of every occurrence that was, in their opinion, related to alcohol consumption. While the diary method is rarely used in academic marketing research, it has a strong track record as a 'tried and tested methodology in other disciplines', particularly in the social sciences (Patterson, 2005 , p. 143) and amongst practitioners. Considered a relatively innovative and under-utilised method, even for qualitative researchers, the diary method offers a good opportunity 'to capture rich insights into processes, relationships, settings, products, and consumers' (Patterson, 2005, p. 142) in the context of the diarists' daily lives (Bolger et al., 2003). Consumer diaries create an opportunity for observation even when a researcher cannot participate in a process or event relevant to the topic under investigation. It would not be possible for researchers to observe real-life behaviours of students during alcohol consumption; therefore, the diaries provided a record of activities and thoughts which occurred in their natural environment, uninfluenced by the presence of an observer. However, one of the main problems researchers face when using the diary method is that there must be a trade-off between sample size, study duration, and frequency and depth of details recorded; previous studies using the method have ranged from five days to four months in duration (Smith et al., 2003).

In Phase 2, a different group of 82 participants from the same pool of students enrolled at the same university, and aged 20-21, including 48 females and 34 males, was divided into 14 groups to prepare consumer collages. The preparation and presentation of collages was an extracurricular activity conducted as a part of the Marketing Research course. The task was voluntary, was not assessed, and participants were not rewarded in any way. As the participants were all marketing students, their motivation was primarily the opportunity to familiarise themselves with an innovative and rarely used (in Poland) research method. Only nine students decided not to take part in the task. For the purpose of this article only four collages, prepared by female-only groups, were selected for analysis, as the remaining 10 
collages, prepared by male-only or mixed-gender groups, fall beyond the scope of this paper, which is to explore female consumers' motivations and perceptions of their extreme alcohol consumption. The four groups consisted of 24 students in total. This number was deemed sufficient to reach theoretical saturation. Previously, similar studies using projective techniques have reported data collected from 16 informants (Tantiseneepong et al., 2012).

All groups were run in three sessions, with five groups working simultaneously in the first two sessions, and four groups in the last session. The students were asked to bring a variety of popular magazines which they read regularly in order to use materials that reflect their worldview and communication style; further materials were also provided by the researchers. Each group was told to produce a collage entitled 'Alcohol as part of a student's life'. They were given a piece of paper (format B2: $50 \times 70.7 \mathrm{~cm}$ ), glue and scissors, and were asked to cut out relevant materials to construct a collage within 45 minutes. Several earlier studies used a similar approach to the development of collages (Hogg and Savolainen, 1998; Banister and Hogg, 2001; Nguyen and Roedder, 2001). In line with a study by Belk et al. (1997), the students were encouraged to try and express their 'feelings, intuitions, imaginings, fantasies, and associations'. They were asked to use photographs, pictures, diagrams, patterns, words, letters or whole sentences in order to create and communicate their own understanding of the given subject. Markers were also provided to enable students to make connections between various elements of their collages. Their theme - 'Alcohol as part of a student's life' - as well as discussions between them and the materials used, were the only stimuli to contribute to the preparation of the collages. Similarly to Phase 1, the task was relatively non-directive, and aimed to explore what participants themselves identified as being relevant to the theme (Piacentini and Banister, 2006). The researchers did not interfere with the groups' discussions during the preparation of the collages, as the end result was supposed to reflect the students' own uninterrupted thoughts and discussions. The deliberate lack of any imposed structure was intended to enhance the differences between groups, highlighting the possible variety of approaches to the same subject. Once all the collages were assembled, the researchers collected them and brought them back to the class a week later. Each group then presented an interpretation of their collage. Participants were encouraged to comment on any aspect of the collage creation process, collage structure and materials used. When questioned about the way they created their collages, participants stated that they had worked out their concept for their collage through discussions and had tried to achieve a consensus on each of its elements. On the one hand, this kind of approach allows individuals to hide behind the group responsibility for the content of their collage; however, on the other, each participant is encouraged towards greater openness and sincerity in creating its content. During the course of each group presentation, the students were questioned by the researchers in order to better identify the reasons behind their selection and layout of images, pictures and words, and the meanings therein. All presentations and discussions were filmed using a digital camcorder. All collected verbal interpretations and pictorial descriptions were analysed by classifying them into the categories that emerged (Donoghue, 2000). The collages were treated as visual representations of ideas, which connected fragmentary pictures embodying feelings and concepts. These objects were given meaning by the participants through their perceived relationship with each other. In order to increase the validity of the findings, both researchers conducted a separate thematic analysis of the diaries, collages and presentation transcripts in order to identify indicative findings. When a common ground was established with respect to major themes, negative cases were explored to determine their contribution to the understanding and complexity of the main themes.

\section{Findings}


Both sets of data - the individual diaries and the collages - were thematically analysed, and in the case of the collages participants' additional verbal commentaries were used. The analysis of the data identified a number of key themes. Many of these - given the character and unstructured nature of the data-gathering method - overlapped one another, and thus in this section the principal topics are drawn out. In order to give the analysis and discussion more structure, the themes are divided into two major issues: drinking motives and control and limits. These themes build on and develop themes proposed by Smith and Berger (2010) in their analysis of interviews with 10 undergraduate females in the US.

\section{Drinking motives}

Despite the very young age of our participants, drinking to cope emerged from the diaries and collages as one of the key drinking motives, which was consistent with earlier studies by Kelly-Weeder (2008), Smith and Berger (2010), and Stewart et al. (2001). Alcohol was presented by our female participants as a solution to a wide range of stressful situations, from facilitating social interactions to coping with heavy workloads at work and university in the case of collages, and from painful break-ups to threats of job loss in the case of diaries. Although drinking to cope was identified by Kelly-Weeder (2008) as one of the key drinking motives and a strong predictor of alcohol use among female students (Kelly-Weeder, 2008), it was presented by our female informants in both diaries and collages as an issue which affected both women and men. A typical example of using alcohol as a strategy to cope with stress, for example when an individual could not identify a simple solution or did not know how to deal with a problem, was when their first reaction was to reach for alcohol. This type of avoidance-oriented and emotion-focused coping strategy (Folkman and Lazarus, 1984; Piacentini and Banister, 2006) helped participants to manage the emotions caused by stress, but did not solve the problem. However, our participants also highlighted that this kind of alcohol use as a form of escape did not concern everyone, but only those people who needed additional stimulation to achieve their aims:

Nowadays a lot of young people have problems with stress, they have nowhere to go, they can't escape their problems or don't know how to deal with stress, and the majority of them reach for alcohol. $\left(\mathrm{C}^{1}\right.$-Fig.1)

...it was a time when things were not going well in my life. Frequent alcohol consumption was for me a way to escape from stress, difficult thoughts, and constant questions. The solution was effective, but short-term. (D2)

...to overcome barriers, after alcohol even girls feel more confident... (C-Fig.4)

It's the same at work, people who have just met and don't know each other, thanks to alcohol they can be more open, have courage to socialise... (C-Fig.3)

The main drinking motive which featured quite prominently in the diaries, collages and participants' commentaries was desire to socialise (McNeela and Bredin, 2010; Rolfe et al., 2009). For female students social interactions were an opportunity to consume alcohol, try new types of drinks, and meet their "friends' friends", which was captured on one of the collages by a slogan stating "Every week new inspirations" (Fig.2). Alcohol was shown as something to be consumed with friends, as one of the participants mentioned - No bottle [of alcohol] wants to be on its own. All four collages contained images of many different types of

\footnotetext{
${ }^{1}$ Throughout this article text in italics refers to informants' verbal commentaries in collages (C) and diaries (Dn - with $\mathrm{n}$ referring to one of five female participants), while text with double inverted commas represents direct quotations from students' collages.
} 
alcohol, and one of them included a sentence stating, "Because your day has many flavours, feel the enjoyment" (Fig.4). In their commentaries, our female participants explained that there was a type of alcohol for every social situation, moment in life, or even for every party. And even when they decided to stay at home, their diaries frequently described feelings of guilt associated with not being able to go out and drink with friends. Drinking was a form of liberation, en-route to freedom and friendship (Lyons and Willott, 2008; McNeela and Bredin, 2010). Not surprisingly, given the importance of students' social lives, almost all groups emphasised integration as one of the most important outcomes of the social consumption of alcohol (Young et al., 2005). The influence of alcohol was considered not only in terms of pleasure from consumption, but also pleasure from consuming alcohol with other people. They spoke about alcohol's ability to facilitate the integration of people from different cultures and sub-cultures, and of different ages. One of the collages had a circular shape (Fig.3), which was presented as a metaphor for integration, where alcohol was a factor holding people together. Further, a table on this collage was shown as a symbol of integration, as people usually get together behind a table. A similar theme emerged from the diaries, many of which contained statements similar to the following two examples:

Thanks to alcohol I found it so much easier to socialise with a large group of my girlfriend's friends, I didn't feel uncomfortable although I knew only two people. (D2)

Surely students drink quite a lot and quite often, but from my point of view it's not a problem. Let's be honest - alcohol facilitates integration, [and the] atmosphere after parties is much more social: shared memories, conversations, etc. (D1)

Interestingly, all images interpreted by our female participants as symbolising integration contained only male characters, for example drunk men dressed as sailors (Fig.4), which indicates that some aspects of alcohol consumption are still perceived in a gendered way (Iyer and Debevec, 1986; Rolfe et al., 2009). One of the female participants explained the perceived differences between drinking behaviour of men and women in the following way:

We wanted to show both female and male sides, we know for example that guys when they drink they form a special bond, while girls get more courage. (C-Fig.4)

Another motive for social alcohol consumption that emerged from our study was the desire to impress fellow students, in particular their male friends, by appropriating their drinking behaviours and attitudes. This captures the way in which the convergence of male and female alcohol consumption happens (Carpenter et al., 2007). Alcohol consumption became, for our female informants, a form of conspicuous consumption, which is practised to acquire a certain social status within a group of students. For example, two of the collages (Fig.2 and Fig.4) presented negative consequences of alcohol consumption in what was interpreted by informants as humorous situations that students should be proud of. Other pictures showed a crawling student (Fig.2) and a picture representing students with blurred vision after drinking to a risky level (Fig.4). These behaviours were seen as a badge of honour and a rite of passage for students who want to belong to the group. The male drinking style was presented and interpreted by female participants as a form of bonding. Further, female participants recognised their male colleagues' heavy drinking as an attempt to impress other students, even when their behaviours posed a significant risk to their health. Copying their behaviours was, for them, a strategy to be liked and to fit in. Female participants' expectations were that alcohol would facilitate their social interactions with their male colleagues. Unexpectedly, unlike men, the women depicted on the collages (Fig.4) prepared by female participants were presented in sexually provocative poses, and their intentions were emphasised by statements such as "hunting for occasion" and "guys for sale". 


\section{Control and limits}

Another important aspect of alcohol consumption, which featured in both the diaries and collages, focused on the limits of consumption. In the diaries, with their personal and livedexperience character, informants tried to reflect on their consumption limits; in contrast, the group collages did not show any concern towards issues of limiting consumption. The collages presented rather dismissive attitudes toward this aspect, which was highlighted by comments emphasising the flexibility of consumption limits and a lack of limits in terms of quantity and frequency of alcohol consumption. Heavy alcohol consumption was shown as "having a good time", with hardly any consideration given to its potential negative consequences, as indicated in Wechsler and Nelson (2008). In fact, there was an underlying assumption among our female participants that time at university is best spent drinking and socialising, while priority to studying is only given during exams. On one of the collages (Fig.2), a semester at university was shown in the form of a board game, where students move from September to December by drinking and having fun, while January is dominated by coffee. Throughout the semester, informants' preparation for classes was depicted as being accompanied by alcohol consumption. For example, one collage (Fig.4) showed an image of an intoxicated male student with text saying "studying sober [you] risk death and injury", and "pleasure" further below. For our female participants, alcohol consumption was shown as a game of finding their alcohol consumption limits without exceeding them, so as to enjoy the positive consequences of alcohol without having to deal with the negative ones, which brings to mind the notion of 'calculated hedonism' (Szmigin et al., 2008). The whole aim of the game was to find one's own limits, as illustrated in the following discussion:

Participant: In a way, alcohol consumption is a game, which means if we exceed certain limits this game becomes dangerous...

Moderator: So is this game about searching for those limits?

Participant: Yes

Further, in the exploration of their consumption limits, participants' attention became focused on the issue of control. Griffin et al. (2012) define self-control as 'the deliberate, conscious, effortful control over behaviour, attention, thoughts, emotions, performance, and impulses'. Balancing between negative and positive consequences of alcohol consumption, participants explored the meaning and importance of both internal and external control. References to curbing consumption due to religious reasons, such as Lent, All Saints' Day and Christmas Eve (which is traditionally alcohol-free in Poland), was common in the students' diaries. This is rather unsurprising, as Christianity remains an important part of Polish culture among young people (Kubacki and Skinner, 2006). On the collages, on the other hand, one of the groups used the slogan "under full control" (Fig.1), which was posed as a kind of warning, but used in an ironic way. This was again similar to the notion of 'calculated hedonism' introduced by Szmigin et al. (2008). When the problem with lack of internal or self-control emerged on some of the collages, their focus was redirected toward finding sources of external control. On one of the collages (Fig.1), which was in a shape of a bottle, the informants depicted a policeman covering the neck of the bottle. The role of the policeman was described as symbolising an external form of control, under which those who drink alcohol heavily did not exceed the limits:

Participant: It's a kind of control over everything, control over heavy alcohol consumption... 
Moderator: Is it an external control?

Participant: We think everyone should control themselves, but this is a kind of symbol [of external control].

While our female informants focused in their collages on the limits of consumption and internal and external control, two groups also explored some negative consequences of heavy alcohol consumption, which, interestingly, were mostly associated with men. This is consistent with Rúdólfsdóttir and Morgan's findings (2009). For example, one collage (Fig.1) presented an image of an aggressive-looking man holding a beer in one hand and a meat tenderiser in another. One student reported:

Here we have a man, who is busy drinking his beer and watching telly, sitting with some kind of a meat tenderiser. Some people become aggressive after alcohol... mostly men are aggressive after alcohol... it may happen among women, but we think that in [general] it concerns men... it may also be a symbol of excessive consumption leading to a pathology. (C - Fig.1)

The negative consequences of alcohol consumption were also frequently associated by our female informants with men (Rúdólfsdóttir and Morgan, 2009). Examples provided in the diaries included arguments and brawls, getting into trouble with police, inappropriate public behaviours and drink-driving. Here, however, unlike in earlier research where problem drinking was assimilated by women into their drinking behaviours (Lyons et al., 2006; Lyons and Willott, 2008; Rolfe et al., 2009), these kinds of behaviours were clearly condemned by our female informants, who criticised them for being immature:

My brother's friend came to us because my brother didn't meet him where they agreed to meet. He is in a band and it was the first day of their tour. My brother, 26 years old, was so drunk after a party that he didn't hear his mobile ringing. When he saw his friend, he got up, took a shower, and off they went. Too much alcohol, lack of any responsibility or imagination, and he didn't even feel sorry - quite the opposite! He looked 'proud' and joked all the time! (D1)

\section{Discussion and conclusions}

This study contributes empirical support for more research into the evolving drinking culture among female students to ensure that social marketing programmes reflect the reality of female students' drinking experiences, motivations and perceptions. Our findings indicate that the female informants' perceptions of their drinking culture were coloured by their understanding of what they refer to as the male drinking culture. And while they very clearly identified the many negative aspects that they perceived to be associated with the male drinking culture (arguments and brawls, getting into trouble with police, inappropriate public behaviours and drink-driving), our female informants pointed toward what they saw as positive and desirable aspects of the male drinking culture: having fun, social integration and bonding. As the similarities between female and male drinking patterns increase (Carpenter $e t$ al., 2007; Young et al., 2005), within social marketing and consumer studies the majority of existing research still treats students' heavy alcohol consumption as if there were no differences between female and male students. This study sought to extend our understanding of young female consumers' motivations and perceptions of their heavy alcohol consumption using consumer diaries and collages as research tools. Using methods other than traditionally dominating alcohol consumption research surveys, interviews and focus groups gives researchers an opportunity to tap into previously under-explored areas of alcohol consumption, and identifies the many issues influencing female students' drinking. This 
research contributes to the existing literature by deepening our understanding of the unique characteristics of female undergraduate students' drinking, and identifying the areas of convergence between male and female alcohol consumption. Further, it explores the motivations behind these convergence processes, and highlights areas in which differences between genders are still strong.

The changing drinking culture among young women has been observed in earlier studies (Boland et al., 2006; Rickards et al., 2004; Wechsler et al., 2002; Young et al., 2005), and this study attempted to identify some of the unique characteristics and directions in this changing drinking culture with specific reference to female undergraduate students. In order to develop a more comprehensive understanding of the culture and its changes, some drinking motives were explored, such as drinking to cope, drinking to socialise and integrate, and drinking as a form of conspicuous consumption. Strong evidence of the use of alcohol to cope with stress and problems is particularly worrying, especially in the light of links between depressive symptoms and binge drinking (Pirkle and Richter, 2006). Further, problems with setting limits on consumption and internal and external control over consumption were also discussed. As self-control has been identified as an important tool in reducing high-risk drinking (Baumeister et al., 2007; Griffin et al., 2012; Posner and Rothbart, 2000), problems with establishing limits on consumption, and ignorance with respect to internal control mechanisms in the hope of finding sources of external control, pose particular challenges to social marketers. Some of the themes emerging from this study were also identified in earlier research (Kelly-Weeder, 2008; Liu and Kaplan, 1996; Stewart et al., 2001). While Measham and Ostergaard (2009) attributed the changes in women's drinking to their growing independence, the findings from this research come closer to Young et al.'s (2005) argument that female students' drinking was not only about gender equality, but more about attracting positive attention from their male peers and raising their social position among maledominated drinking groups. Similarly to other studies, our participants associated problem drinking with men (Rúdólfsdóttir and Morgan, 2009).

Some of the earlier studies into alcohol consumption argue that new insights need to be generated when more traditional research techniques fail to provide satisfactory information (Fry, 2007). One of the main advantages of the multi-method research design turned out to be the complementary nature of the methods used (Greene et al., 1989). While the diary method provided the individual participants with an opportunity for deep critical reflection which was based on real events, the collages allowed us to capture young females' motivations and perceptions of their alcohol consumption from a social-group perspective, wherein consumption behaviours, practices and rituals are negotiated in the same way as the construction of collages - through collaborative effort, conflict and agreement. Further, the collages better enabled us to explore implicit emotions, attitudes and opinions, along with their intensity, importance and the relationships between them. While the diaries revealed individual respondents' attitudes and opinions, the collages contextualised these by capturing the social dynamics that influence the culture of extreme drinking among female students. Another important advantage of using a projective technique such as collages comes to the fore in contexts like the study of heavy alcohol consumption, where the individuals involved do not always fully comprehend the value and importance of changing their behaviour. It may be difficult for respondents to express themselves verbally in more traditional research methods such as diaries, and therefore collages allow researchers to better "understand consumers' inner thoughts and feelings about products, services, people, behaviours and situations" (Chang, 2001). As both tasks in this study (diaries and collages) were designed to be conducted in a non-directive way, the respondents were given freedom to interpret the 
research topic from their own perspective. The female participants often chose to go beyond their own motivations and perceptions of themselves, and contextualised these through the prism of their perceptions of the culture of intoxication that is prevalent among their fellow male students.

\section{Limitations}

This research is limited by a small sample recruited from one university, and the indicative findings should be used in further research. One important limitation which emerged during the research process was the fact that the data generated through the collages was very sloganistic. This was counterintuitive and may be a reflection of the fact that the respondents were using various magazines and newspapers, wherein headlines and titles are used to attract readers' attention; the same idea may have been used, therefore, by our respondents to achieve the same aim - to express their ideas in a catchy and stimulating way. Further, the process of collage creation, similarly to a process of creating a poster, lends itself more towards visuallyattractive slogans than descriptive design.

We also need to acknowledge that juxtaposing two different research methods, such as diaries and collages, creates many problems for researchers when it comes to data analysis. Diaries contain personal experiences, feelings and opinions based on real-life events and expressed in a direct fashion, while projective techniques rely on photographs, pictures, diagrams, patterns, words and letters to explore often hidden or unconscious emotions and attitudes. Further, the process of negotiating common ground in the creation of collages may potentially obstruct the differences between participants. However, as the subject of heavy alcohol consumption can be sensitive to some female participants, working in groups allows individuals to be more open, honest and courageous in presenting their opinions as they cannot be attributed to a single individual.

\section{Future research and implications}

Despite differences in the nature of the data gathered through the diaries and collages, the findings offer unique insights into female students' motivations and perceptions of heavy alcohol consumption, which stems from the complementary nature of both methods. Each method, used separately, offers a narrow view of the problem that focuses on individual experiences and reflections (in the case of diaries), and social interactions and negotiations (in the case of collages). Juxtaposing the two perspectives makes it possible to develop our understanding of alcohol consumption, and the interaction between individual and social factors shaping the culture of intoxication.

In terms of research implications, it became evident that more attention needs to be paid to the motivations and drinking practises of female undergraduate students. For example, their willingness to appropriate some of their male friends' drinking behaviours and attitudes indicated a significant shift in their drinking culture which has led to increased levels of risky alcohol consumption. Therefore, future research should focus on further exploration of these changes in an attempt to understand their meaning, relevance and importance to female students. The consumer collages discussed in this paper offered some indication as to the potential characteristics of the female students' drinking culture. Finally, from a social marketing perspective, more multi-method research is necessary to improve our understanding of the relationship between individual and social factors influencing heavy alcohol consumption. Both groups of factors are often explored separately, yet the decision to engage in binge drinking is an outcome of the interplay between one's personality, selfperception and interests, as well as social pressures such as the student culture of intoxication 
and social identity. Better understanding of female students' drinking culture will help to develop more targeted and effective policies and social marketing programmes to prevent heavy alcohol consumption among female students.

\section{References}

Alcohol Concern (2003), "Women and alcohol", December, available at: http://www.alcoholconcern.org.uk/servlets/doc/768. Accessed 09/07/2012.

Banister, E.N. and Hogg, M.K. (2001), "Mapping the negative self: from 'So not me'. . to 'Just not me"”, Advances in Consumer Research, Vol. XXVIII, pp. 242-248.

Baumeister, R.F., Vohs, K.D. and Tice, D.M. (2007), "The strength model of self-control”, Current Directions in Psycholological Science, Vol.16, pp. 396-403.

Belk, R.W., Gnliz, G. and Askegaard, S. (1997), "Consumer desire in three cultures: results from projective research", Advances in Consumer Research, Vol. 24, pp. 24-28.

Berkowitz, A.D. and Perkins, H.W. (1987), "Recent research on gender differences in collegiate alcohol use", Journal of American College Health, Vol. 36, pp. 123-129.

Black, I. (2006), "The presentation of interpretivist research", Qualitative Market Research: An International Journal, Vol. 9 No. 4, pp. 319-324.

Bloomfield, K., Gmel, G., Neve, R. and Mustonen, H. (2001), "Investigating gender convergence in alcohol consumption in Finland, Germany, the Netherlands and Switzerland", Substance Abuse, Vol. 22, pp. 39-54.

Boland, M., Fitzpatrick, P., Scallan, E., Daly, L., Herity, B., Horgan, J., et al. (2006), "Trends in medical student use of tobacco, alcohol and drugs in an Irish university, 1973-2002", Drug and Alcohol Dependence, Vol. 85, pp. 123-128.

Bolger, N., Davis, A. and Rafaeli, E. (2003), "Diary methods: capturing life as it is lived", Annual Review of Psychology, Vol. 54, pp. 579-616.

Carpenter, R., Fishlock, A. Mulroy, A. Oxley, B., Russell, K., Salter, C., Williams, N. and Heffernan, C. (2007), “After 'Unit 1421': an exploratory study into female students' attitudes and behaviours towards binge drinking at Leeds University", Journal of Public Health, Vol. 30 No. 1, pp. 8-13.

Centres for Disease Control and Prevention (1999), "Youth risk behaviour survey (YRBS)", Department of Health and Human Services, Atlanta, Georgia, USA.

Cismaru, M., Lavack, A.M. and Markewich, E. (2008), "Alcohol consumption among young consumers: a review and recommendations", Young Consumers, Vol. 9 No. 4, pp. 282-296.

Cuneo, A.Z. (1997), “Advertisers target women, but market remains elusive, taking a new look: categories outside traditionally feminine products seek gender's buying power", Advertising Age, November 10, 1, pp. 24-26. 
Dantzer, C., Wardle, J., Fuller, R., Pampalone, S. Z., and Steptoe, A. (2006), “International study of heavy drinking: Attitudes and sociodemographic factors in university students", Journal of American College Health, Vol. 55, pp. 83-89.

Donoghue, S. (2000), "Projective techniques in consumer research", Journal of Family Ecology and Consumer Sciences, Vol. 28, pp. 47-53.

Eccles, S. (2000), “Addictive consumption and women consumers in the UK”, PhD Thesis, Lancaster University.

Elliott, R. (1994), “Addictive consumption: function and fragmentation in postmodernity", Journal of Consumer Policy, Vol. 17 No. 2, pp.159-179.

ESPAD (2007) "European school survey project on alcohol and other drugs", The 2007 ESPAD Report, http://www.espad.org/documents/Espad/ESPAD_reports/2007/ The_2007_ESPAD_Report-FULL_091006.pdf, accessed: 15 February 2012.

Fischer, E. (2002), Panel comments [written notes] "Gender, marketing and consumer Behavior", Maclaran, P. and Tissier-Desbordes, E. (eds.) Association for Consumer Research, Paris, p.259.

Fry, M.-L. (2007), "Looking through the social marketing lens: Research issues and techniques", Australasian Journal of Market and Social Research, Vol. 15 No. 2, pp. 35-44.

Griffin, K.W., Scheier, L.M., Acevedo, B., Grenard, J.L. and Botvin, G.J. (2012), "Long-term effects of self-control on alcohol use and sexual behavior among urban minority young women", International Journal of Environmental Research and Public Health, Vol. 9, pp. 123.

Harrison, R. and Reilly, T.M. (2011), "Mixed methods designs in marketing research", Qualitative Market Research: An International Journal, Vol. 14 No. 1, pp.7-26

Hayward, K. and Yar, M. (2006), "The 'chav' phenomenon: Consumption, media and the construction of a new underclass”, Crime Media Culture, April, Vol. 2 No. 1, pp. 9-28.

Hill, S.C., Thomsen, S.R., Page, R.M. and Parrott, N. (2005), “Alcohol advertisements in youth-oriented magazines: persuasive themes and responsibility messages", American Journal of Health Education, Vol. 36 No. 5, pp.258-265.

Hogg, M.K., and Savolainen, M.H. (1998), "Symbolic consumption and the situational self", European Advances in Consumer Research, Vol. 3, pp.11-16.

Iyer, E. and Debevec, K. (1986), "Sex roles and consumer perceptions of promotions, products, and self: what do we know and where should we be headed?", in Lutz, R. (ed.) Advances in Consumer Research, Vol. 13, pp.210-214

Kelly-Weeder, S. (2008), "Binge drinking in college-aged women: Framing a gender-specific prevention strategy", Journal of the American Academy of Nurse Practitioners, Vol. 20, pp. 577-584. 
Kelly-Weeder, S. and Edwards, E. (2011), "Co-occurring binge eating and binge drinking in college women”, The Journal for Nurse Practitioners, Vol. 7 No. 3, pp. 207-213.

Kubacki, K. and Skinner, H. (2006), "Poland: exploring the relationship between national brand and national culture", Journal of Brand Management, Vol. 13 No. 4-5, pp.284-299.

Kuntsche, E., Knibbe, R., Gmel, G. and Engels, R. (2005), "Why do young people drink? A review of drinking motives", Clinical Psychology Review, Vol. 25, pp. 841-861.

Kypri, K., Cronin, M. and Wright, C. S. (2005), "Do university students drink more hazardously than their nonstudent peers?", Addiction, Vol. 100, pp. 713-714.

Lazarus R.S. and Folkman, S. (1984), Stress, appraisal and coping, Springer Publishing Company: NewYork.

Lyons, A.C. and Willott, S.A. (2008), “Alcohol consumption, gender identities and women's changing social positions”, Sex Roles, Vol. 59, pp. 694-712.

Lyons, A.C., Dalton, S.I. and Hoy, A. (2006), "Hardcore drinking': portrayals of alcohol consumption in young women's and men's magazines”, Journal of Health Psychology, Vol. 11, pp. 223-232.

Liu, X. and Kaplan, H.B. (1996), "Gender-related differences in circumstances surrounding initiation and escalation of alcohol and other substance use/abuse", Deviant Behavior, Vol. 17, pp. 71-106.

Makara-Studzinska, M. and Urbańska, A. (2007), "Binge drinking patterns among young people from rural areas of Lublin province," Annals of Environmental and Agricultural Medicine, Vol. 14, pp. 45-49.

MacNeela, P. and Bredin, O. (2010), "Keeping your balance: freedom and regulation in female university students' drinking practices", Journal of Health Psychology, Vol. 16, pp. 284-293.

Measham, F. and Ostergaard, J. (2009), "The public face of binge drinking: British and Danish young women, recent trends in alcohol consumption and the European binge drinking debate", Probation Journal: The Journal of Community and Criminal Justice, Vol. 56 No. 4, pp. 415-434.

Nguyen, L., and Roedder John, D. (2001), “Abercrombie and Finch - that's me: brand names in children's self concept presented in just do it! the influence of brand names on children's lives", Advances in Consumer Research, Vol. XXVIII, pp. 48.

O'Donnell, K.A., Wallers, A.S. and Wardlow, D.L. (1998), "Gender and team sports: the arena where agency meets communion”, in Fischer, E. (ed.) Gender and Consumer Behavior, Advances in Consumer Research, Vol. 4, pp.159-178.

O’Malley, P.M. and Johnston, L.D. (2002), "Epidemiology of alcohol and other drug use among American college students", Journal of Studies on Alcohol, Vol. 14, pp. 23-39. 
Otnes, C. and McGrath, M.A. (2001), "Perceptions and realities of male shopping behaviour", Journal of Retailing, Vol. 77 No. 1, pp. 111-137.

Patterson C.E. and Hogg, M.K. (2004), "Gender identity, gender salience and symbolic consumption", in Gender and Consumer Behavior, Advances in Consumer Research, Vol. 7, pp. 1-33.

Park, C.L. (2004) "Positive and negative consequences of alcohol consumption in college Students", Addictive Behaviors, Vol. 29, pp. 311-321.

Park, C.L. and Levenson, M.R. (2002), "Drinking to cope among college students:

Prevalence, problems and coping processes", Journal of Studies on Alcohol, Vol. 63, No.4, pp. 486-497.

Parks, K. and Scheidt, D. (2000), "Male bar drinkers perspective on female bar drinkers", Sex Roles, Vol. 42, pp. 927-941.

Piacentini, M.G.and Banister, E.N. (2006). "Getting hammered?: Students coping with Alcohol”, Journal of Consumer Behaviour Theory and Practice, Vol. 5, March-April, pp. 145156.

Piacentini, M.G. and Banister, E.N. (2009), "Managing Anti-Consumption in an Excessive Drinking Culture", Journal of Business Research, Vol. 62, pp. 279-288.

Pirkle, E.C. and Richter, L. (2006), "Personality, attitudinal and behavioral risk profiles of young female binge drinkers and smokers", Journal of Adolescent Health, Vol. 38 No. 1, pp. 44-54.

Plant, M. (1997), Women and alcohol: Contemporary and historical perspectives, London: Free Association Books.

Posner, M.I. and Rothbart, M.K. (2000), "Developing mechanisms of self-regulation", Development and Psychopathology, Vol. 12, pp. 427-441.

Read, J.P., Wood, M.D., Kahler, C.W., Maddock, J.E. and Palfai, T.P. (2003), "Examining the role of drinking motives in college student alcohol use and problems", Psychology of Addictive Behaviors, Vol. 17, No. 1, pp. 13-23.

Rickards, L., Fox, K., Roberts, C., Fletcher, L. and Goddard, E. (2004), Living in Britain, no. 31. Results from the 2002 General Household Survey, London: Stationery Office.

Roche, A. M. and Deehan, A. (2002), "Women's alcohol consumption: emerging patterns, problems and public health implications", Drug and Alcohol Review, Vol. 21, pp. 169-178.

Rolfe, A., Orford, J. and Dalton, S. (2009), "Women, alcohol and femininity: A discourse analysis of women heavy drinkers' accounts", Journal of Health Psychology, Vol. 14, pp. 326-335. 
Rúdólfsdóttir, A.G. and Morgan, P. (2009), “Alcohol is my friend': young middle class women discuss their relationship with alcohol”, Journal of Community and Applied Social Psychology, Vol. 19, pp. 492-505.

Smith, A., Sparks, L., Hart, S. and Tzokas, N. (2003), "Retail loyalty schemes: results from a consumer diary study", Journal of Retailing and Consumer Services, Vol. 10, pp. 109-119.

Smith, M.A. and Berger, J.B. (2010), “Women's ways of drinking: college women, high-risk alcohol use, and negative consequences", Journal of College Student Development, Vol. 51 No. 1, pp. 35-49.

Stewart, S.H., Loughlin, H.L. and Rhyno, E. (2001), "Internal drinking motives mediate personality domain-drinking relations in young adults", Personality and Individual Differences, Vol. 30, pp. 271-286.

Szmigin, I., Griffin, Ch., Mistral, W., Bengry-Howell, A., Weale, L. and Hackley, Ch. (2008), "Re-framing 'binge drining' as calculated hedonism - empirical evidence from the UK", International Journal of Drug Policy, Vol. 19 No. 5, pp. 359-366.

Tadajewski, M. (2006), "Remembering motivation research: toward an alternative genealogy of interpretive consumer research", Marketing Theory, Vol. 6 No. 4, pp. 429-466.

Tantiseneepong, N., Gorton, M. and White, J. (2012), "Evaluating responses to celebrity endorsements using projective techniques", Qualitative Market Research: An International Journal, Vol. 15 No. 1, pp. 57-69.

Tyler, I. (2008), “'Chav Mum, Chav Scum' Class Disgust in Contemporary Britain”, Feminist Media Studies, Vol. 8, No.1, pp. 17-34.

Tyssen, R., Vaglum, P., Aasland, O.G., Nina T. Gronvold, N.T. and Ekeberg, O. (1998), "Use of alcohol to cope with tension, and its relation to gender, years in medical school and hazardous drinking: a study of two nation-wide Norwegian samples of medical students", Addiction, Vol. 93, No. 9, pp. 1341-1349.

Wechsler, H., Lee, J.E., Kuo, M. and Lee, H. (2000), "College binge drinking in the 1990s: a continuing problem - results of the Harvard School of Public Health 1999 College Alcohol Study", Journal of American College Health, Vol. 48 No. 10, pp. 199-210.

Wechsler, H., Lee, J.E., Kuo, M., Seibring, M., Nelson, T.F. and Lee, H. (2002), “Trends in college binge drinking during a period of increased prevention efforts: findings from 4 Harvard School of Public Health College alcohol study surveys: 1993-2001", Journal of American College Health, Vol. 50 No. 5, pp. 203-217.

Wechsler, H. and Nelson, T.F. (2008), "What we have learnt from the Harvard School Of Public Health College alcohol study: focusing attention on college student alcohol consumption and the environmental conditions that promote it", Journal of Studies on Alcohol and Drugs, Vol. 69 No. 4, pp. 1-10.

Woodruffe-Burton, H., Eccles, S. and Elliott, R. (2002), "The effect of gender on addictive consumption: reflections on men, shopping and consumption meaning", "Gender, marketing 
and consumer behavior", Maclaran, P. and Tissier-Desbordes, E. (eds.) Advances in Consumer Research, Vol. 6, pp. 239-256.

Young, A.M., Morales, M., McCabe, S.E., Boyd, C.J. and D’Arcy, H. (2005), "Drinking like a guy: frequent binge drinking among undergraduate women", Substance Use and Misuse, Vol. 40, pp. 241-267. 